\title{
Barriers to identifying and obtaining CME: a national survey of physicians, nurse practitioners and physician assistants
}

\author{
Maureen O'Brien Pott', Anissa S. Blanshan², Kelly M. Huneke 3 , Barbara L. Baasch Thomas ${ }^{3}$ and David A. Cook ${ }^{3,45^{*}}$ (D)
}

\begin{abstract}
Background: CPD educators and CME providers would benefit from further insight regarding barriers and supports in obtaining CME, including sources of information about CME. To address this gap, we sought to explore challenges that clinicians encounter as they seek CME, and time and monetary support allotted for CME.

Methods: In August 2018, we surveyed licensed US clinicians (physicians, nurse practitioners, and physician assistants), sampling 100 respondents each of family medicine physicians, internal medicine and hospitalist physicians, medicine specialist physicians, nurse practitioners, and physician assistants (1895 invited, 500 [26.3\%] responded). The Internet-based questionnaire addressed barriers to obtaining CME, sources of CME information, and time and monetary support for CME.

Results: The most often-selected barriers were expense (338/500 [68\%]) and travel time ( $N=286$ [57\%]). The source of information about CME activities most commonly selected was online search $(N=348$ [70\%]). Direct email, professional associations, direct mail, and journals were also each selected by $>50 \%$ of respondents. Most respondents reported receiving $1-6$ days $(N=301$ [60\%]) and $\$ 1000-\$ 5000(n=263$ [53\%]) per year to use in CME activities. Most (> 70\%) also reported no change in time or monetary support over the past 24 months. We found few significant differences in responses across clinician type or age group. In open-ended responses, respondents suggested eight ways to enhance CME: optimize location, reduce cost, publicize effectively, offer more courses and content, allow flexibility, ensure accessibility, make content clinically relevant, and encourage application.
\end{abstract}

Conclusions: Clinicians report that expense and travel time are the biggest barriers to CME. Time and money support is limited, and not increasing. Online search and email are the most frequently-used sources of information about CME. Those who organize and market CME should explore options that reduce barriers of time and money, and creatively use online tools to publicize new offerings.

Keywords: Education, medical, continuing, Credentialing, Licensure, medical, Marketing, Workplace learning

\footnotetext{
* Correspondence: cook.david33@mayo.edu

${ }^{3}$ Mayo Clinic School of Continuous Professional Development, Mayo Clinic College of Medicine and Science, Rochester, MN, USA

${ }^{4}$ Office of Applied Scholarship and Education Science, Mayo Clinic College of Medicine and Science, Rochester, MN, USA

Full list of author information is available at the end of the article
}

C C The Author(s). 2021 Open Access This article is licensed under a Creative Commons Attribution 4.0 International License, which permits use, sharing, adaptation, distribution and reproduction in any medium or format, as long as you give appropriate credit to the original author(s) and the source, provide a link to the Creative Commons licence, and indicate if changes were made. The images or other third party material in this article are included in the article's Creative Commons. licence, unless indicated otherwise in a credit line to the material. If material is not included in the article's Creative Commons licence and your intended use is not permitted by statutory regulation or exceeds the permitted use, you will need to obtain permission directly from the copyright holder. To view a copy of this licence, visit http://creativecommons.org/licenses/by/4.0/ The Creative Commons Public Domain Dedication waiver (http://creativecommons.org/publicdomain/zero/1.0/) applies to the data made available in this article, unless otherwise stated in a credit line to the data. 


\section{Background}

All health professionals engage to varying degrees in continuous professional development (CPD) - a lifelong process of "improv[ing their] professional knowledge, skills, or performance." [1] Continuing medical education (CME) is a subset of CPD that awards credit for designated activities. Most clinicians (including physicians, nurse practitioners, and physician assistants) must participate regularly in CME to maintain licensure. Problems have been identified in the way CME is delivered, financed, regulated, and evaluated [2-6], leading to strategic changes in CME delivery, evaluation, and regulation [7-9]. Less well documented, however, are the barriers and challenges ("pain points") that individual clinicians encounter as they try to meet their CME requirements, and the sources of information they use in identifying CME opportunities.

Most studies examining barriers to CPD are over a decade old [10-14], and given changes in both clinical practice and CME infrastructure their findings may be of limited contemporary relevance. A recent survey of US physicians found that time and money were the top barriers $[1,15]$, but this study did not involve nonphysicians nor did it explore how clinicians' CME and CPD activities are financially supported. Another recent survey of physicians, general practice nurses, and pharmacists in Scotland [16] reported the availability of protected time for CME, but did not address other potential barriers or supports. Although prior surveys suggest that finding relevant CPD is a barrier $[1,10,17,18]$, we are not aware of any contemporary research contrasting sources by which clinicians learn about CME opportunities.

CPD educators and CME providers would benefit from further insight regarding barriers and supports in obtaining CME, and sources clinicians use to identify CME offerings. To address this gap, we conducted a national survey of US physicians, nurse practitioners, and physician assistants, addressing questions:

1. What challenges do clinicians encounter as they seek CME, and what support (time and money) do they receive for CME?

2. From what sources of information do clinicians find out about CME opportunities?

3. How do these responses vary by clinician type, specialty, and age?

4. What suggestions do clinicians have for improving CME?

\section{Methods}

\section{Overview}

We surveyed licensed US clinicians (physicians, nurse practitioners, and physician assistants) using an
Internet-based questionnaire that addressed pain points in obtaining CME, sources of information regarding CME, and level of support for CME in terms of time and money. Another paper using other questions from this survey has been published, addressing how clinicians select among available CME modalities [19].

\section{Sampling and human subjects}

Clinicians were eligible if they had completed a CME activity through any provider in the preceding 24 months. Clinicians employed by our institution or a closely affiliated institution were excluded. We used stratified random sampling to select clinicians from an external vendor database (Dynata), and invited participants until we achieved our target sample of 100 respondents from each of five clinician types: family medicine physicians, internal medicine and hospitalist physicians, physicians in other internal medicine subspecialties, nurse practitioners (all medical specialties), and physician assistants (all medical specialties). This sample was selected for practical reasons, namely that the research team is responsible for CME programming for this audience. We offered respondents a modest incentive (a gift card, charitable contribution, or similar product, valued at most \$44). The study was deemed exempt by the Mayo Clinic Institutional Review Board.

\section{Instrument}

A group of administrators and researchers with experience in CME, including specific expertise in CME operations and marketing, developed the survey questionnaire. We identified relevant issues by reviewing prior internal (unpublished) and published surveys [1, 10, 14], from personal experience, and through discussions with clinicians, CME course directors, operations managers, and marketing analysts. This report presents responses for a subset of questions from the full survey, including items regarding barriers in obtaining CME, sources of information when looking for CME offerings, and time and monetary support for CME. Items used checklists or ordinal response options (see Results and the e-Box for specific wording). We also asked two open-ended questions about "ways [our institution] can enhance their [live, in-person or online] educational courses?" The survey questions are provided verbatim in the e-Box.

\section{Survey administration}

Survey administration was conducted via email from $\mathrm{Au}$ gust 7 to August 14, 2018 by Endeavor Management Consulting. Waves of email invitations were sent each day, with one reminder on August 13. Each email contained an individually-tracked link to an Internet-based questionnaire hosted on Qualtrics (www.qualtrics.com). The survey closed after achieving the target response 
$(N=100)$ for each clinician subgroup. All responses were anonymous.

\section{Analyses}

We compared demographics of respondents and nonrespondents using chi-squared. For most outcomes (those with an approximately normal distribution), we used ANOVA to explore differences in across subgroups (clinician specialty and age), and used Tukey's test to contrast subgroups for statistically significant models. For questions about time and money allotment we used the Kruskall-Wallis test. All analyses were performed using SPSS v25. Given the large sample size and the large number of independent statistical tests, we used $p<.01$ as the threshold of statistical significance.

Two authors $(\mathrm{AB}, \mathrm{KH})$ iteratively and independently coded responses to the two open-ended questions, to inductively identify key themes. They then worked together to refine the list of themes into a concise list of potential actions that might mitigate barriers to CME.

\section{Results}

To achieve our target of 500 responses (100 per clinician subgroup) we invited 1895 clinicians (overall response rate, 26.3\%); namely 975 family medicine and internal medicine/hospitalists (21\% response), 199 specialists (50\% response), and 721 nurse practitioners and physician assistants (28\% response). Respondents and nonrespondents were similar in gender, age, and geographical region ( $p \geq 0.04$; see Table 1$)$.

\section{Barriers to $\mathrm{CME}$}

When asked to select the most important "pain point" from a checklist, expense (selected by 338/500 [68\%] respondents) was the most frequently selected, followed by travel time $(N=286$ [57\%]), discovering/searching for appropriate CME offerings $(N=143[29 \%])$, and topic not applicable to daily practice $(N=133$ [27\%]) (see Table 2).

There were no statistically significant differences in barriers across clinician types. There was one statistically significant difference by age groups, with those $\geq 60$ (61/ 74 [82\%]) more likely to select expense than those $<40$ $(55 / 92[60 \%])(p=.01$; see e-Table 1$)$.

\section{Sources of information}

When asked to identify where they get information about CME activities, the source of information most commonly selected was online search $(N=348$ [70\%]). Other sources selected by $>50 \%$ of respondents included email, professional associations, direct mail brochures, and journals. Mentors (4\%) and supervisors (3\%) were identified least often. See Table 3 for details on additional sources.

We found statistically significant differences $(p<.01)$ across clinician types for four (of 14) information sources; in each instance, nurse practitioners were more likely than another clinician type to select that information source. Specifically, nurse practitioners were more likely (70/100) than internal medicine physicians (47/ 100 ) to select professional associations as an information source; more likely (71/100) than physician assistants (44/100) and internal medicine physicians (39/100) to select direct mail brochures; more likely $(48 / 100)$ than specialists $(26 / 100)$ to select healthcare organizations; and more likely (39/100) than all other groups (all $\leq 19 \%)$ to select in-person handouts.

We found statistically significant differences $(p<.01)$ by age group for three information sources. Specifically, those 50-59 years old were more likely (43/87 [49\%]) than those 40-49 (32/123 [26\%]) to select healthcare organizations as an information source; those $50-59$ were more likely $(59 / 87[68 \%])$ than those < $40(40 / 92[44 \%])$ to select direct mail brochures; and those $\geq 60$ (56/

Table 1 Characteristics of Respondents and Non-respondents

\begin{tabular}{|c|c|c|c|c|}
\hline Domain & Subdomain & Respondents No. (\%); $N=500$ & $\begin{array}{l}\text { Non-respondents } \\
\text { No. }(\%) ; N=1395\end{array}$ & $\mathbf{P}$ \\
\hline \multirow[t]{2}{*}{ Gender } & Female & $251(50 \%)$ & $742(53 \%)$ & .25 \\
\hline & Male & $249(50 \%)$ & $653(47 \%)$ & \\
\hline \multirow[t]{4}{*}{ Region of USA } & Northeast & $140(28 \%)$ & $330(24 \%)$ & .04 \\
\hline & Midwest & $95(19 \%)$ & $292(21 \%)$ & \\
\hline & South & $146(30 \%)$ & $491(35 \%)$ & \\
\hline & West & $111(23 \%)$ & $279(20 \%)$ & \\
\hline \multirow[t]{4}{*}{ Age (years) ${ }^{b}$} & $<40$ & $92(24 \%)$ & $189(27 \%)$ & .59 \\
\hline & $40-49$ & $123(33 \%)$ & $203(29 \%)$ & \\
\hline & $50-59$ & $87(23 \%)$ & $161(23 \%)$ & \\
\hline & $\geq 60$ & $74(20 \%)$ & $147(21 \%)$ & \\
\hline
\end{tabular}

\footnotetext{
a $N=392$ and 1392 for region, for respondents and non-respondents respectively, due to incomplete data in database
}

${ }^{\mathrm{b}} \mathrm{N}=376$ and 700 for age, for respondents and non-respondents respectively, due to missing responses 
Table 2 Barriers to Obtaining CME, by Clinician Type

\begin{tabular}{|c|c|c|c|c|c|c|c|}
\hline Barrier & $\begin{array}{l}\text { All: No. (\%); } \\
\mathrm{N}=500\end{array}$ & $\begin{array}{l}\text { FM: No.; } N= \\
100\end{array}$ & $\begin{array}{l}\text { IM/H: No.; N = } \\
100\end{array}$ & $\begin{array}{l}\text { Spec.: No.; } N= \\
100\end{array}$ & $\begin{array}{l}\text { NP: No.; } N= \\
100\end{array}$ & $\begin{array}{l}\text { PA: No.; } N= \\
100\end{array}$ & $p$ \\
\hline Expense & $338(67.6 \%)$ & 67 & 65 & 60 & 77 & 69 & .13 \\
\hline Travel time & $286(57.2 \%)$ & 57 & 55 & 63 & 51 & 60 & .48 \\
\hline $\begin{array}{l}\text { Discovering/searching for appropriate } \\
\text { CME offerings }\end{array}$ & $143(28.6 \%)$ & 28 & 29 & 27 & 34 & 25 & .70 \\
\hline Not applicable to daily practice & $133(26.6 \%)$ & 25 & 21 & 30 & 25 & 32 & .41 \\
\hline Ability to easily track CME credits earned & $59(11.8 \%)$ & 16 & 12 & 11 & 14 & 6 & .25 \\
\hline
\end{tabular}

Responses were selected from a checklist, in response to the question: "What are the biggest gaps/pain points in obtaining CME offerings? [check all that apply]" Abbreviations: FM Family Medicine, IM/H Internal Medicine / Hospitalist, Spec. Internal Medicine Specialist, NP Nurse Practitioner, PA Physician Assistant

$74[76 \%])$ were more likely than both those <40 (46/ $92[50.0 \%])$ and those $40-49(64 / 123[52 \%])$ to select email communication.

\section{Time and monetary support}

We asked participants to indicate how much time and money they were allotted to support CME activities, and how much this had changed over the past 24 months (see Table 4). The most frequently cited number of days allotted for CME was 1-6 days per year $(301 / 500 ; 60 \%)$. The most frequently cited dollar amount for CME support was USD \$1000 - \$5000 per year $(263 / 500[53 \%])$. No statistically significant differences $(p>.01)$ in current time or monetary support were identified by clinician type or age (see Table 4 and e-Table 3).
The vast majority of respondents $(>70 \%)$ indicated no change over the past 24 months in time or monetary support (see Table 4). Less than 10\% indicated that support for CME activities has increased in this time period, and about $14 \%$ indicate that support has actually decreased (see Table 4). Again, we found no statistically significant differences by clinician type or age groups (Table 4 and e-Table 3).

\section{Opportunities for enhancing CME}

We inductively and iteratively analyzed the 773 free-text responses to two questions asking for suggestions to enhance in-person and online CME. From this analysis we identified eight proposed enhancements, many of which will help mitigate barriers noted above. See Table 5 for additional quotes in support of each enhancement.

Table 3 Sources of Information about CME Courses, by Clinician Type

\begin{tabular}{|c|c|c|c|c|c|c|c|}
\hline Information Source & $\begin{array}{l}\text { All: No. } \\
(\%) ; \\
N=500\end{array}$ & $\begin{array}{l}\text { FM: No.; } N= \\
100\end{array}$ & $\begin{array}{l}\text { IM/H: No.; } N= \\
100\end{array}$ & $\begin{array}{l}\text { Spec.: No.; } N= \\
100\end{array}$ & $\begin{array}{l}\text { NP: No.; } N= \\
100\end{array}$ & $\begin{array}{l}\text { PA: No.; } N= \\
100\end{array}$ & $\mathbf{p}$ \\
\hline Online & $348(69.6 \%)$ & 70 & 64 & 68 & 69 & 77 & .38 \\
\hline Direct email communication & $296(59.2 \%)$ & 68 & 50 & 62 & 63 & 53 & .06 \\
\hline Professional associations & $293(58.6 \%)$ & 61 & $47^{a}$ & 50 & $70^{\mathrm{a}}$ & 65 & .003 \\
\hline Brochures via direct mail & $263(52.6 \%)$ & 57 & $39^{a}$ & 52 & $71^{\mathrm{a}}$ & $44^{\mathrm{a}}$ & $<.001$ \\
\hline Journals & $260(52.0 \%)$ & 45 & 50 & 56 & 57 & 52 & .44 \\
\hline Peers/word of mouth & $234(46.8 \%)$ & 41 & 42 & 42 & 52 & 57 & .08 \\
\hline Healthcare organizations & $165(33.0 \%)$ & 32 & 29 & $26^{a}$ & $48^{a}$ & 30 & .009 \\
\hline Medical societies & $163(32.6 \%)$ & 39 & 34 & 37 & 26 & 27 & .18 \\
\hline $\begin{array}{l}\text { Brochures via in-person } \\
\text { handout }\end{array}$ & $104(20.8 \%)$ & $15^{\mathrm{a}}$ & $16^{a}$ & $15^{\mathrm{a}}$ & $39^{a}$ & $19^{a}$ & $<.001$ \\
\hline Doximity & $54(10.8 \%)$ & 11 & 9 & 16 & 9 & 9 & .43 \\
\hline Physician liaison & $27(5.4 \%)$ & 4 & 6 & 9 & 5 & 3 & .39 \\
\hline Online chat forums & $24(4.8 \%)$ & 4 & 5 & 6 & 5 & 4 & .96 \\
\hline A mentor & $21(4.2 \%)$ & 6 & 5 & 5 & 3 & 2 & .61 \\
\hline My supervisor & $15(3.0 \%)$ & 3 & 2 & 1 & 6 & 3 & .31 \\
\hline
\end{tabular}

Responses were selected from a checklist, in response to the question: "How do you find out about CME courses?"

Abbreviations: FM Family Medicine, IM/H Internal Medicine / Hospitalist, Spec. Internal Medicine Specialist, NP Nurse Practitioner, PA Physician Assistant

a Subgroup responses are statistically significantly different from one another using Tukey's test $(p<.01)$; in each instance, nurse practitioners' selections were more frequent than those of the other indicated clinician type(s) 
Table 4 Time and Monetary Support Available for CME, by Clinician Type

\begin{tabular}{|c|c|c|c|c|c|c|c|c|}
\hline Domain & Response & $\begin{array}{l}\text { All: No. (\%); } N= \\
500\end{array}$ & $\begin{array}{l}\text { FM: No.; } N= \\
100\end{array}$ & $\begin{array}{l}\text { IM/H: No.;N = } \\
100\end{array}$ & $\begin{array}{l}\text { Spec.: No.;N= } \\
100\end{array}$ & $\begin{array}{l}\text { NP: No.; } N= \\
100\end{array}$ & $\begin{array}{l}\text { PA: No.; } N= \\
100\end{array}$ & $p$ \\
\hline \multirow[t]{4}{*}{ Time allotment } & 0 days & $59(11.8 \%)$ & 10 & 10 & 17 & 11 & 11 & .03 \\
\hline & $1-6$ days & $301(60.2 \%)$ & 52 & 55 & 44 & 77 & 72 & \\
\hline & $\geq 7$ days & $121(24.2 \%)$ & 30 & 29 & 34 & 12 & 16 & \\
\hline & Irrelevant ${ }^{\mathrm{a}}$ & $19(3.8 \%)$ & 7 & 6 & 5 & 0 & 1 & \\
\hline \multirow[t]{3}{*}{ Change in time allotment } & Less & 79 (15.8\%) & 17 & 14 & 16 & 17 & 15 & .33 \\
\hline & No change & $374(74.8 \%)$ & 73 & 71 & 80 & 77 & 73 & \\
\hline & More & $47(9.4 \%)$ & 10 & 15 & 4 & 6 & 12 & \\
\hline \multirow[t]{3}{*}{ Monetary allowance } & $\begin{array}{l}<\$ 1000 / \\
\text { none }\end{array}$ & $219(43.8 \%)$ & 40 & 50 & 49 & 47 & 33 & .30 \\
\hline & $\begin{array}{l}\$ 1000- \\
\$ 5000\end{array}$ & $263(52.6 \%)$ & 55 & 48 & 41 & 52 & 67 & \\
\hline & $>\$ 5000$ & $18(3.6 \%)$ & 5 & 2 & 10 & 1 & 0 & \\
\hline \multirow{4}{*}{$\begin{array}{l}\text { Change in monetary } \\
\text { allowance }\end{array}$} & Less & $78(15.6 \%)$ & 11 & 11 & 11 & 17 & 18 & .21 \\
\hline & No change & $358(71.6 \%)$ & 68 & 71 & 71 & 75 & 73 & \\
\hline & More & $45(9.0 \%)$ & 10 & 14 & 7 & 7 & 7 & \\
\hline & No support & 29 (5.8\%) & 11 & 4 & 11 & 1 & 2 & \\
\hline
\end{tabular}

Questions asked about current time or monetary support from their practice for CME activities each year, and how the amount of time/monetary support had changed over the past 24 months

Abbreviations: FM Family Medicine, IM/H Internal Medicine / Hospitalist, Spec. Internal Medicine Specialist, NP Nurse Practitioner, PA Physician Assistant

a Indicates clinicians who would "Not [be] willing to be away from my practice"

Table 5 Suggested Actions to Enhance CME Activities, and Supporting Quotes

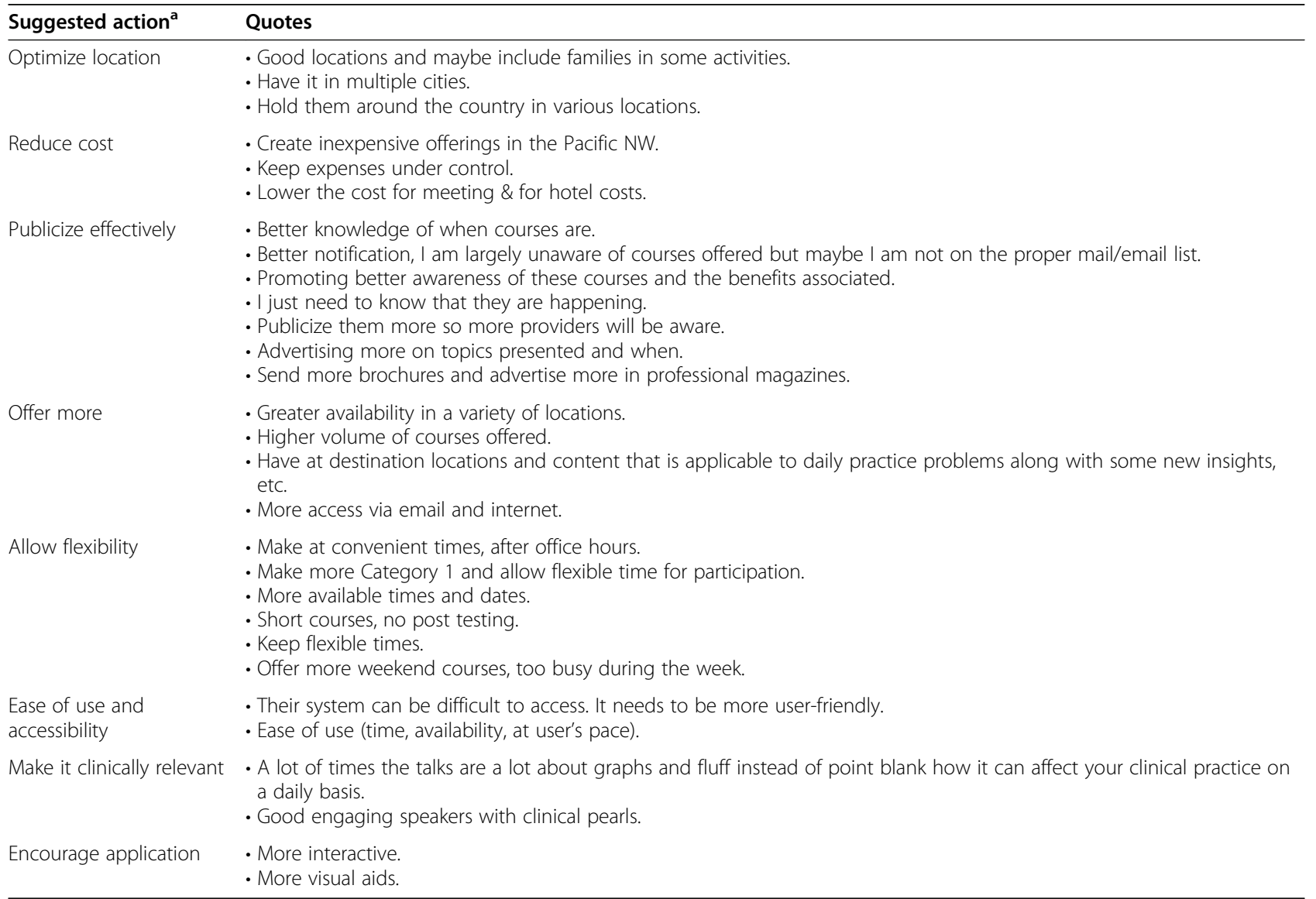

\footnotetext{
a Suggestions derived from inductive analysis of 773 free-text comments
} 


\section{Optimize location}

Location matters, whether it is conveniently nearby or in a "desirable destination." One respondent mentioned "having [courses] in multiple cities around the country and at locations near the airport." Another suggested having "a variety of specialty specific courses in desirable location with some free time," while another mentioned having " 15 credits per day $\times 2$ days in desirable location."

\section{Reduce cost}

Clinicians are willing to pay for CME, but would like it to cost less, whether in-person or online. Many respondents specifically used phrases such as "cost," "cost effective," "decrease cost," and "inexpensive offerings." It is not just the cost of registration, but the overall cost to attend; as one respondent suggested, "Lower the cost for meeting and hotel costs." Notably, one respondent expressed concern that their "CME allowance has not changed in 30 years, but the cost of courses has gone up."

\section{Publicize effectively}

Clinicians want to know about their options and prefer that information be disseminated well in advance. As one respondent noted, "I just need to know when they are happening." Another said, "Find a way to reach those who could use the CME." Other specific suggestions included: "better advertisement of availability," "better outreach," and "better publicity of the courses."

\section{Offer more}

Clinicians want more options for CME. Respondents indicated they would like more CME content, addressing a greater variety of topics, offered in higher volumes ("more offerings," "more locations," "more variety of topics," and "more courses available"). One person requested, "Gear them to nurse practitioners as well as MDs."

\section{Allow flexibility}

Clinicians need flexibility in course structure and scheduling, and this is true for both in-person and online courses. For in-person courses, participants commented "convenient time on weekend," "flexibility in dates and length of course," "vary the time of events- I like 5 pm Pacific; Sat \& Sundays ok with me." There was also a suggestion that the "days should be shorter so that they could enjoy the location."

For online courses, participants suggested "allowing more up to date practices and ability to go back if topic is misunderstood rather than feeling rushed," "available 24 hours 7 days," "better times" and "flexible times and do at your own pace."

\section{Ensure ease of use and accessibility}

Ease of use and accessibility are critical to customer satisfaction and success. Multiple respondents mentioned "access," "availability" and "having resources available at the user's pace." They specifically called for "wider availability of topics," "easy availability of numerous topics at a reasonable price," "time availability," and "wider availability [of] options."

\section{Make it clinically relevant}

Course content needs to be relevant to daily practice ("relevant topics and how it will be used in practice"). This involves both selecting clinically-relevant topics for a course or session, and making content within a session clinically relevant. Respondents requested speakers who shared "clinical pearls" or "pitfalls," and encouraged a clear link to how the topic can affect their clinical practice using phrases such as "more topics used in my clinic," "more family practice topics," and "more specific courses for my sub-specialty." A commonly-suggested approach was to use "plenty of clinical scenarios."

\section{Encourage application}

Clinicians recognize the need for opportunities to apply what they have learned. Several respondents requested that courses be "more hands-on." Others endorsed activities that promote application of learning to authentic cases, such as having "lectures ... structured for daily practice routines supplemented with challenging cases [and] pitfalls for each topic."

\section{Discussion}

This national survey of 500 US physicians, nurse practitioners, and physician assistants found that expense and travel time are the biggest barriers. Clinicians most often rely on online search, direct email communications, professional associations, mailed brochures, and journal advertisements to find out about CME opportunities. Time and monetary support for CME has not changed in the past 24 months. These findings were generally similar across clinician types and age groups. Open-ended responses highlight several opportunities for improvements in CME delivery, including optimizing location, lowering costs, publicizing courses more effectively, providing opportunities for application, and making content clinically relevant.

\section{Limitations}

Our study has several limitations that allow the possibility that our findings do not represent the larger population of US clinicians. The email administration format might have preferentially selected for individuals more comfortable with online and email communication, and the short response period may have given preference to 
early responders. The relatively low overall response rate also raises the possibility of a suboptimally-representative sample, although respondents and nonrespondents were similar in observed demographics. Additionally, we did not invite physicians in non-medicine specialties. Although the survey developers had extensive experience in CME and marketing, the choice of survey topics and final wording of survey items represents another potential limitation. Strengths include the large national sample and the inclusion of nurse practitioners, physician assistants, and physicians in various medicine specialties.

\section{Integration with prior work}

Our findings elaborate on prior surveys about CME [1, $10-15,20]$ by focusing on barriers, and time and monetary supports (and how these have changed). This study also prioritizes the channels by which clinicians find out about CME opportunities, and proposes enhancements that may mitigate some barriers.

\section{Implications for practice and future research}

We highlight several implications of our work. First, CME providers seeking to publicize an upcoming event will find our prioritized list of information sources (i.e., marketing channels) useful. While it is perhaps unsurprising that user-initiated Internet search led this list, this finding underscores the need for CME providers to maintain a strong online presence. Search engine optimization $[21,22]$ can enhance the likelihood that a given website will be ranked highly in a user-initiated "organic" search (search results comprised of unadvertised, unpaid links). The preference for email aligns with findings from a survey conducted by a commercial vendor (88\% preference for CME information email vs. direct mail, journals, or social media) [23]. Although search engine optimization and strategic email marketing are well-established approaches in consumer marketing, they have received little dedicated study in CME. We note anecdotally that our institution has had mixed experiences with direct email marketing for CME; whether this represents idiosyncrasies related to our specific email strategy, or a cautionary note regarding this modality for CME generally, remains unexplored.

Second, most clinicians have limited resources (less than one week and $\$ 5000$ per year) allotted for CME, and this allotment is not changing for most clinicians. As one clinician pointed out, unchanged monetary support translates to an overall reduction in purchasing power over time. Perhaps more importantly, the modest time allotment highlights that CME cannot always require travel. Previous research suggests that overall cost and topical relevance are the most influential factors in selecting CME opportunities requiring travel [15]. Online CME has the potential to overcome barriers of both out-of-pocket cost and time required for travel [24], could exploit several of the opportunities noted above (e.g., flexibility, accessibility, and volume), and is now widely accepted across all age groups and clinician types $[1,19,20]$. However, we remind readers that the instructional designs, delivery approaches, and implementation strategies that foster effective online learning typically differ from those used in face-to-face instruction (thus requiring unique faculty skillsets, innovative tools, and novel course designs) $[25,26]$, and that the development cost of online learning activities can be high [27].

Third, our data indicate that nurse practitioners tended to select a variety of information sources with higher frequency than other clinician types. These findings, together with the quote from one respondent, could indicate that nurse practitioners feel obligated to cast a broader net to find CME courses relevant to their needs. They could also simply reflect different response patterns for this group. Pending further study, our findings suggest that nurse practitioners may benefit from more, and more publicity about, CME options that target their needs.

Fourth, the CPD landscape has been transformed by the COVID-19 pandemic, with online learning filling the void created by curtailed face-to-face offerings. Now that CME providers and consumers have experienced the advantages of distance learning, it seems almost certain that some degree of transformation will endure. This in turn may affect the salience of some barriers (e.g., cost, time, flexibility). Repeating a survey such as ours in the post-COVID era may prove insightful.

Finally, our findings support the advantage of a strong infrastructure to support CME as an enterprise. Six of the suggestions to enhance CME (location, cost, publicity, clinical relevance [of the course], and quantity and accessibility of offerings) address issues that extend beyond the teaching within a session, and require operational decisions months or years in advance. While the CME enterprise is often criticized [2-6], our findings suggest that it is nonetheless important. Reduced costs, increased quantity of offerings, and enhanced publicity are all more likely to be achieved through experienced CME providers. This underscores the need to both support and regulate CME providers, as they in turn support clinicians in their pursuit of ongoing professional development.

\section{Conclusions}

Clinicians report that expense and travel time are the biggest barriers to CME. Time and money support is limited, and not increasing. Online search and email are the most frequently-used sources of information about CME. Those who organize and market CME should explore options that reduce barriers of time and money, and creatively use online tools to publicize new offerings. 


\section{Abbreviations}

CPD: Continuous professional development; CME: Continuing medical education

\section{Supplementary Information}

The online version contains supplementary material available at https://doi. org/10.1186/s12909-021-02595-x.

\section{Additional file 1 Online Supplemental Box and Tables: e-Box}

Verbatim Items from Survey Questionnaire. e-Table 1. Barriers in

Obtaining CME, by Age Group. e-Table 2. Sources of Information about CME Courses, by Age Group. e-Table 3. Time and monetary support available for CME, by Age Group.

\section{Acknowledgements}

The authors wish to thank Marilyn E. Marolt and Michael W. O'Brien for their help in planning, testing, and implementing the survey.

\section{Authors' contributions}

Author MOP had full access to all the data in the study and takes responsibility for the integrity of the data and the accuracy of the data analysis. All of the authors (MOP, ASB, KMH, BLBT, DAC) jointly defined the study objectives and hypotheses, interpreted study results, drafted and revised the manuscript, and approved the final manuscript.

\section{Authors' information}

Twitter: David A.Cook, @CookMedEd.

\section{Funding}

There were no external sources of funding

\section{Availability of data and materials}

All data generated or analysed during this study are included in this published article and its supplementary information files.

\section{Declarations}

\section{Ethics approval and consent to participate}

The study was deemed exempt by the Mayo Clinic Institutional Review Board Response to the survey implied consent to participate.

\section{Consent for publication}

Not applicable.

\section{Competing interests}

The authors declare that they have no competing interests.

\section{Author details}

${ }^{1}$ Planning Services, Mayo Clinic, Rochester, MN, USA. ${ }^{2}$ Medical Professionals Marketing, Mayo Clinic, Rochester, MN, USA. ${ }^{3}$ Mayo Clinic School of Continuous Professional Development, Mayo Clinic College of Medicine and Science, Rochester, MN, USA. ${ }^{4}$ Office of Applied Scholarship and Education Science, Mayo Clinic College of Medicine and Science, Rochester, MN, USA. ${ }^{5}$ Division of General Internal Medicine, Mayo Clinic, Rochester, MN, USA.

Received: 9 July 2020 Accepted: 5 March 2021

Published online: 19 March 2021

\section{References}

1. Cook DA, Blachman MJ, Price DW, West CP, Berger RA, Wittich CM. Professional development perceptions and practices among US physicians: a cross-specialty National Survey. Acad Med. 2017;92:1335-45.

2. Institute of Medicine. Redesigning continuing education in the health professions. Washington, DC: The National Academies Press; 2010

3. Hager M, Russell S, Fletcher SW. Editors. Continuing Education in the Health Professions: Improving Healthcare Through Lifelong Learning. New York: Josiah Macy, Jr. Foundation; 2007.

4. Forsetlund L, Bjørndal A, Rashidian A, Jamtvedt G, O'Brien MA, Wolf FM, Davis D, Odgaard-Jensen J, Oxman AD. Continuing education meetings and workshops: effects on professional practice and health care outcomes.
Cochrane Database of Systematic Reviews. 2009(2)CD003030. https://doi org/10.1002/14651858.CD003030.pub2.

5. Grudniewicz A, Kealy R, Rodseth RN, Hamid J, Rudoler D, Straus SE. What is the effectiveness of printed educational materials on primary care physician knowledge, behaviour, and patient outcomes: a systematic review and meta-analyses. Implement Sci. 2015;10:164.

6. Ivers N, Jamtvedt G, Flottorp S, Young JM, Odgaard-Jensen J, French SD, et al. Audit and feedback: effects on professional practice and healthcare outcomes. Cochrane Database Syst Rev. 2012;6:CD000259.

7. McMahon GT. What do I need to learn today?--the evolution of CME. N Engl J Med. 2016;374:1403-6.

8. Nissen SE. Reforming the continuing medical education system. JAMA. 2015;313:1813-4.

9. Davis DA, Prescott J, Fordis CM Jr, Greenberg SB, Dewey CM, Brigham T, et al. Rethinking CME: an imperative for academic medicine and faculty development. Acad Med. 2011;86:468-73.

10. Price DW, Overton CC, Duncan JP, Wamsley DA, Havens C, Steinbruegge J, et al. Results of the first National Kaiser Permanente Continuing Medical Education Needs Assessment Survey. Permanente J. 2002;6:76-84.

11. Curran VR, Keegan D, Parsons W, Rideout G, Tannenbaum D, Dumoulin N, et al. A comparative analysis of the perceived continuing medical education needs of a cohort of rural and urban Canadian family physicians. Can J Rural Med. 2007;12(3):161-6.

12. Stewart GD, Khadra MH. The continuing medical education activities and attitudes of Australian doctors working in different clinical specialties and practice locations. Aust Health Rev. 2009;33(1):47-56.

13. Stewart GD, Teoh KH, Pitts D, Garden OJ, Rowley DI. Continuing professional development for surgeons. Surgeon. 2008;6:288-92.

14. Vollmar HC, Rieger MA, Butzlaff ME, Ostermann T. General Practitioners' preferences and use of educational media: a German perspective. BMC Health Serv Res. 2009:9:31.

15. Cook DA, Price DW, Wittich CM, West CP, Blachman MJ. Factors influencing Physicians' selection of continuous professional development activities: a cross-specialty National Survey. J Contin Educ Heal Prof. 2017:37:154-60.

16. Cunningham DE, Alexander A, Luty S, Zlotos L. CPD preferences and activities of general practitioners, registered pharmacy staff and general practice nurses in NHS Scotland - a questionnaire survey. Education for primary care : an official publication of the Association of Course Organisers, National Association of GP Tutors, World Organisation of Family Doctors. 2019;30:220-9.

17. Goodyear-Smith F, Whitehorn M, McCormick R. Experiences and preferences of general practitioners regarding continuing medical education: a qualitative study. New Zealand Med J. 2003;116:U399.

18. Salinas GD. Trends in physician preferences for and use of sources of medical information in response to questions arising at the point of care: 2009-2013. J Contin Educ Heal Prof. 2014:34(Suppl 1):S11-6.

19. O'Brien Pott M, Blanshan AS, Huneke KM, Baasch Thomas BL, Cook DA. What influences choice of continuing medical education modalities and providers? A National Survey of U.S. physicians, nurse practitioners, and physician assistants. Acad Med. 2020;96:93-100.

20. Cook DA, Blachman MJ, Price DW, West CP, Baasch Thomas BL, Berger RA et al. Educational Technologies for Physician Continuous Professional Development: a National Survey. Acad Med. 2018;93:104-12.

21. Berman $R$, Katona $Z$. The role of search engine optimization in search marketing. Mark Sci. 2013;32:644-51.

22. Lemos JY, Joshi AR. Search engine optimization to enhance user interaction. Paper presented at: 2017 International conference on I-SMAC (IoT in social, Mobile, analytics and cloud); February 2017; Palladam, Tamil Nadu, India.

23. Medical Marketing Services Inc. 2020 Continuing Medical Education Survey Results. Available at: https:/www.mmslists.com/survey-results. Accessed 30 Apr 2020.

24. Cook DA. Web-based learning: Pro's, Con's, and controversies. Clin Med. 2007;7:37-42

25. Triola MM, Huwendiek S, Levinson AJ, Cook DA. New directions in elearning research in health professions education: report of two symposia. Med Teach. 2012;34:e15-20.

26. Cook DA, Triola MM. What is the role of e-learning? Looking past the hype. Med Educ. 2014:48:930-7.

27. Cook DA. The value of online learning and MRI: finding a niche for expensive technologies. Med Teach. 2014;36:965-72.

\section{Publisher's Note}

Springer Nature remains neutral with regard to jurisdictional claims in published maps and institutional affiliations. 